\title{
GENDER DIFFERENCES IN ATTITUDES TOWARDS OBOW EXAMS: THE CASE OF A DEVELOPING COUNTRY
}

\author{
Mary Ann B. El Rassi \\ Saint Jospeh University, Beyrouth, Lebanon
}

\begin{abstract}
Despite the increased research interest on the implementation of Open Book Open Web exams in developed countries, there has been very little systematic studies that investigated the difference in gender experience and the cognitive process that could affect attitude towards OBOW exams compared to the traditional ones in developing countries. This paper aims at filling this gap in knowledge by comparing OBOW and traditional exam methods. Several exams in two different contextual settings were done and in three different high schools. The exams were divided into two phases, midterms and finals and several methods were adopted. The sample included 307 students in addition to three focus groups that helped us to identify important factors. Factors such as gender, emotional tension/anxiety, technology self-efficiency, perceived ease of use were important cues that predicted academic performance. At the end of this research paper, we propose a preliminary model that could be detested further with a larger sample.
\end{abstract}

\section{KEYWORDS}

Open Book Open Web Exams, Academic Performance, Electronic Learning, Developing Countries

\section{INTRODUCTION}

In a world where globalization is considered as a multidimensional phenomenon, e-leaning appears to be one of the emerging trends and is increasingly weighing not only in developed economies but also in developing economies (Guàrdia, Crisp \& Alsina, 2017). It is an innovative tool, mainly for subjects that necessitate multimedia and collaboration. As a result, the student profile has changed economically, culturally and socially as new online teaching techniques have emerged, encouraging students from all over the globe to enroll in e-distance learning (Joi, Camille \& Krista, 2011). This has resulted in an impressive change in the educational technology. A transformation that has been of a major interest to scholars and journals recently which have led to the creation of a stream of literature that examined this topic from different angles such as blended learning techniques and wholly online techniques among others (Steve, Ferrante and Heppard, 2016). Despite this new revolution, one facet of the academic life has hardly changed at all, which is the traditional exam model for conducting exams that still dominates. Given the fact, that most of the modern academic institutions use the internet platform to communicate with their students and exchange information, they still fear conducting online exams and prefer to rely on a physical examination that is physically monitored. We cannot deny the fact that most of this new generation is an internet savvy and depend largely on the use of the net very often in their daily activities. Therefore, this paper is centered on the following question: What could possibly be the influential factors that affect the students' attitude towards Open-Book Open-Web exams? Whereas developing countries differ from developed countries in terms of culture and ICT infrastructure (El Rassi, 2020; El Rassi, 2018; El Rassi \& Harfouche, 2016). Our major objective in this research is to better understand the students' attitude towards an OBOW in an era where it appears that there is a gap in literature when it comes to assessing this issue in a developing country. To accomplish the study's main objective outlined in this paper, we proceed by presenting a literature review concerning the employment of e-learning in the education system, the OBOW. 


\section{E-LEARNING, OBWO AND TRADITIONAL MEANS}

In the following section we present an overview of the literature concerning the above mentioned subject. Our major concern is to provide an overview about e-learning and OBOW. The traditional closed book examination methods are able to investigate the student's knowledge based on their learning (Guàrdia et al., 2017). These methods are entirely based on the student's memory and is considered as an assessment instrument that is more likely to foster deep learning. Thus, sometimes, these methods are not very efficient in assessing the students' knowledge and have been questioned by many scholars. It is also found that traditional exams sometimes result in higher scores but those same students might fail to pass the competitive recruitment exams when required because they lack the freedom of analyzing (Steve et al,2016). In order to overcome this issue, some scholars have encouraged educators to reassess their traditional format by proposing an open -book-open web exam among other options (Steve et al, 2016). Thus, a new trend had emerged where some universities for example have started to accommodate grades from traditional exams to OBOW to award program degrees. This new pattern called OBOW allows students to use electronic devices during their exam assessment. It reflects a major change and difference from the traditional format as it allows the student to take full advantage of all the available resources through the Web. Another interesting outcome of the OBOW examination is that questions represent real world problems which requires general knowledge and research and this minimizes the chance of copying or cheating by students (Steve et al, 2016). Even though this looks quite easy to be done by cheating or copying, a submission procedure such as plagiarism software could be used to detect any academic fraud. The major idea in the OBOW model is to urge the students to think in a conceptual way to analyze and solve a given problem or mini-case and that is by employing their knowledge and expertise that they have acquired during their course of studies (Miller and Young-Jones, 2012). In addition to the use of plagiarism software, and the time constraints that the student faces when conducting his exam (for a period of 2 or 3 hours), it would be impossible for them to outsource the solution as the accomplice should be first familiar with the subject which makes it more difficult for them to cheat. Therefore, may authors have considered that the OBOW exams represent an efficient way to engage students whether they are monitored for cheating as in the traditional exams or not (Steve et al,2016). Therefore, assessing the cognitive process is very crucial to understanding the factors that affect students' experience in OBOW and traditional exams as students' learning is guided by the way they are assessed.

\section{LITERATURE REVIEW}

The Technology Acceptance Model (TAM) that was proposed by Davis (1986) is one of the most broadly adopted models in theory that was used in different settings and contexts by many authors (Davis et al., 1989; Venkatesh, Morris, Davis, \& Davis, 2003). This model was based on the general human behavior model that is called the theory of reasoned action (Fishbein \& Ajzen 1975) whereas the theoretical basis was to offer an enlightenment of the human computer use behavior that was earlier proposed by Fishbein \& Ajzen (1975). Moreover, this model is interesting to the current study as it has also investigated the applicability and legitimacy to examine students' intention when using e-learning technologies in several studies (Roca et al. 2006). The model considers that the perceived usefulness (PU) and perceived ease of use (PEU) are the antecedent determinant factors to use IT and are considered as the two main constructs of this model as they are able to predict the individual's attitude towards using a certain system. Perceived usefulness is defined as the extent to which an individual believes that using a certain system will improve his job performance. While the perceived ease of use is defined as the extent to which an individual believes that using a certain system will be free of mental and physical effort. PU and PEU are two antecedents that could influence a person's attitude (A) while attitude is perceived as the individual's assessment of his behavior. This attitude (A) is also expected to influence the individual's behavioral intention (BI) and consequently, BI is expected to influence the actual use (AU) of a certain system. Furthermore, the use of technology has also been of a major concern in the literature. Computer anxiety is defined as an individual's apprehension or even fear, when she/he is faced with the possibility of using computers (Simonson et al., 1987). Howard \& Smith (1986) defines computer anxiety as the tendency of a person to experience a level of uneasiness over his or her impending use of a computer. In fact, students' who are using e-learning as new educational tools could have some anxiety towards presenting their exams online (OBOW). Several researches have investigated computer anxiety as a key factor 
in influencing the different types of technology intention such as e-mails and computer usage. Recently, several researches have been conducted in the area of e-learning intention to use to investigate the role of computer anxiety on students' intention (Ndubisi, 2004; Saadé \& Kira 2006). Saadé and Kira (2006) have conducted research to assess the emotional state of students' perception towards online learning system based on the technology intention model (TAM). The authors have extended technology intention model to include Anxiety and Affect as antecedents and for both perceived usefulness and perceived ease of use. The findings from the study indicated that the perceived usefulness of using online system is not determined by the students' computer anxiety. However, it has indirect influence through the perceived ease of use on the students' intention of online learning system. Furthermore, the anxiety has a positive influence on students' intention of using online system. In conclusion, the emotional state has no direct impact on perceived usefulness of an online learning system, whereas, it has power in predicting the ease of use of the online learning system. Ndubisi (2004) has conducted research to investigate the critical factors that influence the student' intention to adopt e-learning in Malaysia. The author examined many factors on students' intention to use the Blackboard system such as users' attitude, subjective norm, perceived behavioral control, perceived usefulness and ease of use of the system. Some of those factors were used to mediate and others to test directly the proposed variables. The findings show that the computer anxiety has contributed significantly and has predicted about $22 \%$ of variation in perceived behavioral control. The findings also indicate that the students with high level of computer anxiety have less perceived behavioral control which will ultimately influences the behavioral intention to use e-learning tools. In brief, computer anxiety seems to be a crucial factor that could influence the e-learning adoption in higher education institutions. Other studies have investigated the computer self-efficacy in e-learning as an antecedent to the TAM model. In a study that was conducted by Madorin \& Iwasiw (1999), the authors have investigated the effect of computer self-efficacy in e-learning in the faculty of nursing. Self-efficacy is an individual's believe about his own ability and incentive to achieve a specific task (Agarwal, Sambamurthy, \& Stair 2000). In the current study it is considered as one's capacity to use a technology to complete a specific task (Venkatesh et al., 2003). The findings of Madorin \& Iwasiw (1999) study revealed that while the computer self-efficacy has a strong effect on PEU, it has an insignificant effect on PU. While several studies have been conducted to examine the self-efficiency influence on the technology intention model (Madorin \& Iwasiw, 1999), the results of these study were different than Venkatish et al. (2003) results. The latter authors have argued that the underlying problem might be low computer self -efficacy and in such cases, a training should be conducted to enhance the user's self-efficiency when using technology which could increase the individual's attitude.

\section{METHODOLOGY}

The research was conducted in a high school that has adopted the web as a support to its teaching methods. Students can connect with their teachers, consult their lessons and grades through an application called pronote. In addition to that, the school has initiated many electronic initiatives and had merged them into their learning processes for their students' access and use. Nevertheless, the traditional learning model is still valid. This paper is based on a comparison between the traditional method examination and the OBOW. Two exams were conducted during the same year and for the same courses, in addition to some focus groups where participants were selected from the students and professors who had experienced both methods that are stated in our paper. The traditional exam was conducted at school and monitored by instructors, while the OBOW exam was made outside the school on a day off and the due time limit was fixed. This had allowed the students to take the test at their convenience and from any place they may choose to be comfortable with. And as the school is an international French school that usually have 3 different campuses in the same city, the students were divided into 3 different groups sharing in common the same educational level (senior high school year) and course offerings. The total number of students that participated in this exam was 307 among which $41 \%$ were male and 59\% were female students and their age range was expected to be 17-18. All three groups have taken the same exam, at the same time without knowing each other or without even knowing that the others have had a similar case. Then we compared the grades of OBOW exams of the students by the same group of students from the traditional closed book exam. As we have targeted three different campuses for the same school and the same courses taken, we have divided our groups into 3 main groups depending on their grades as mentioned before. Having three different locations have helped us a lot because students aren't supposed to be familiar with each other which could decrease the possibility of cheating when doing the first and second phase of the 
exam. Both exams consisted of two phases: the first phase consisted of 30 multiple choice questions and was estimated to be finished within 45 minutes, and students were given 60 minutes. While the second part consisted of a mini case where the students should be able to illustrate and analyze based on their personal knowledge. Once they start, they cannot keep it on hold or save and return to it later. While the second phase consisted of a mini-case analysis that was well-researched, well thought-out scripts along with a reflection that represents the value of this approach for the improvement of students' learning outcome. The second phase couldn't be copied as it was automatically passed through the plagiarism software and was based on their personal writing skill. After finishing the two exams, we then interviewed 3 focus groups to evaluate their experience and assessment of this new experience and compare the differences, if found, in the two adopted models in addition to their instructors. Each focus group was chosen from the three campuses based on their academic level. Sentences and verbatim were selected which had helped us in constructing a questionnaire. Then we carried on our study by sending this questionnaire by email to the same students. In an attempt to detect any possible cheating or difficulties encountered in part I of the OBOW exam, we have estimated that when a student took more than 4 minutes to answer a question, he could possibly be looking to find another alternative with other peers. Considering that 30 multiple choice questions needed between 45 to 60 minutes to be completed and there is no penalty in answering any question falsely, therefore we expected the student to pick any answer if he doesn't know it within a time frame of 3 or 4 minutes' maximum. A previous sample test was done online and in campus with the students to avoid any technical mistakes they might encounter.

\section{RESULTS}

In this section we will start by presenting the results of the exams conducted in both models and their grade scores. Then we proceeded by choosing a focus group that equally represents all three schools. Starting with the first phase of the exam, we have conducted two exams for the same course. One midterm that was done through traditional means, with a pen and paper, while the second was done during the final exam using the OBOW method. Table 1 explains in details the results of the first phase that consisted of a Multiple Choice Question (MCQ) exam. It included 30 questions that equally varied between difficult, medium and easy. In the traditional method, pen and paper, students were monitored in class and the supervisors were able to detect any technical or cheating problems directly on the spot. In the OBOW method, the answers were chosen randomly for each student which means that cheating is not an easy task for them to do due to the time constraints unless they waste their time and efforts to make it happen. The below table shows that the instructors participated in screening the degree of cheating during the examination period. Cheating was evaluated based on the time the students took to finish their exam whether phase one or phase two.

Table 1. QCM exam results comparison

\begin{tabular}{|c|c|c|c|c|c|c|c|}
\hline \multicolumn{7}{|c|}{ Phase 1 : Multiple choice questions (MCQ) - 30 questions- $60 \mathrm{mn}$} & \multirow[b]{2}{*}{$\begin{array}{l}\text { Numbers of } \\
\text { students }\end{array}$} \\
\hline & $\begin{array}{l}\text { Type of } \\
\text { exam }\end{array}$ & $\begin{array}{l}\text { Grp1-execllent } \\
>16 / 20\end{array}$ & $\begin{array}{l}\text { Grp2-good } \\
14 \text { to } 16 / 20\end{array}$ & $\begin{array}{l}\text { Grp3-average } \\
10 \text { to } 14 / 20\end{array}$ & $\begin{array}{l}\text { Grp4-below } \\
\text { average < } \\
10 / 20\end{array}$ & Invalid & \\
\hline \multirow[t]{2}{*}{ School I } & OBOW & 32 & 40 & 24 & 6 & 0 & \multirow[t]{2}{*}{102} \\
\hline & Traditional & 38 & 47 & 16 & 1 & $1 *$ & \\
\hline \multirow[t]{2}{*}{ School II } & OBOW & 44 & 33 & 17 & 3 & $1 *$ & \multirow[t]{2}{*}{98} \\
\hline & Traditional & 45 & 30 & 20 & 2 & $1 *$ & \\
\hline \multirow{2}{*}{$\begin{array}{l}\text { School } \\
\text { III }\end{array}$} & OBOW & 50 & 37 & 14 & 4 & $2 *$ & \multirow[t]{2}{*}{107} \\
\hline & Traditional & 53 & 29 & 22 & 3 & 0 & \\
\hline \multirow{2}{*}{$\begin{array}{l}\text { Total \# } \\
\text { of } \\
\text { students }\end{array}$} & OBOW & $126(41 \%)$ & $110(35.8 \%)$ & $55(18 \%)$ & $13 \quad(6 \%)$ & 3 & \multirow[t]{2}{*}{307} \\
\hline & Traditional & $136(44.22 \%)$ & $106(34.5 \%)$ & $58(18.9 \%)$ & $5(2 \%)$ & 2 & \\
\hline
\end{tabular}


In the first and second groups, the OBOW exam performance reached $41 \%$ for Group 1 compared to $44.22 \%$ for the traditional model and $35.8 \%$ for the OBOW in group 2 compared with $34.5 \%$ in for the traditional model. Summing them together, $76.8 \%$ of the grades in OBOW were slightly lower than $78.7 \%$ in the traditional model. This means that both methods were at the same level of efficiency in the MCQ exam. Cheating in the OBOW was less significant than in the traditional model as it was detected. This difference could be considered insignificant which allows us to state that the two methods we have used were credible and efficient for our study.

Table 2. Mini-case exam results comparison

\begin{tabular}{|c|c|c|c|c|c|c|c|}
\hline \multicolumn{7}{|c|}{ Phase $2:$ Mini case assessment- 90 minutes } & \multirow[b]{2}{*}{$\begin{array}{l}\text { Numbers of } \\
\text { students }\end{array}$} \\
\hline & $\begin{array}{l}\text { Type of } \\
\text { exam }\end{array}$ & $\begin{array}{l}\text { Grp1- } \\
\text { execllent } \\
\text { (above } \\
16 / 20 \text { ) }\end{array}$ & $\begin{array}{l}\text { Grp2-good } \backslash \\
\text { (between } \\
14 / 20 \text { and } 16 \\
/ 20\end{array}$ & $\begin{array}{l}\text { Grp3- } \\
\text { average } \\
\text { between } \\
10 \text { and } \\
14 / 20\end{array}$ & $\begin{array}{l}\text { Grp4- } \\
\text { below } \\
\text { average } \\
<10 / 20\end{array}$ & $\begin{array}{l}\text { Invalid } \\
\text { cheating }\end{array}$ & \\
\hline \multirow[t]{2}{*}{ School I } & OBOW & 35 & 34 & 31 & 1 & $1 *$ & \multirow[t]{2}{*}{102} \\
\hline & Traditional & 28 & 33 & 37 & 4 & 0 & \\
\hline \multirow[t]{2}{*}{ School II } & OBOW & 46 & 32 & 18 & 2 & 0 & \multirow[t]{2}{*}{98} \\
\hline & Traditional & 44 & 30 & 20 & 2 & $2 *$ & \\
\hline \multirow[t]{2}{*}{ School III } & OBOW & 41 & 39 & 22 & 5 & 0 & \multirow[t]{2}{*}{107} \\
\hline & Traditional & 29 & 32 & 39 & 6 & $1 *$ & \\
\hline \multirow{2}{*}{$\begin{array}{l}\text { Total number } \\
\text { of students }\end{array}$} & OBOW & $122(40 \%)$ & $105(34.2 \%)$ & $71(23.1 \%)$ & $8(2.6 \%)$ & 1 & \multirow[t]{2}{*}{307} \\
\hline & Traditional & $101(33 \%)$ & $95(31 \%)$ & $96(31.2 \%)$ & $12(4 \%)$ & 3 & \\
\hline
\end{tabular}

*Cheating

In the second phase, the students were offered a mini case and were expected to have a personal contribution. Unless the student didn't attend the previous seminars, he cannot fulfill the requirements and analyze the case study. For the same reasons as in phase I, a student that has been detected to be wasting time or encountering some technical difficulties was considered either cheating or having technical problems. The OBOW exam performance reached $40 \%$ for group 1 compared to $33 \%$ for the traditional model and $34.2 \%$ in OBOW for group 2 compared to $31 \%$ for the traditional model. Summing them together, 74.2 of the grades in OBOW were scattered between group 1 and group 2 which is higher than the sum of those two groups in the traditional model $(64 \%)$. While cheating in the OBOW was less significant than in the traditional model (1 student in the OBOW took more than 10 minutes in answering 2 questions). Furthermore, a higher number of failing students that scored below the average were identified in the traditional exam. We then proceeded our investigating by choosing three focus groups whereas each focus group consisted of three students and one teacher from each institution in order to evaluate their experience and perspective regarding the pros and cons of this OBOW exam and to note their objections, if any.

\subsection{Focus Groups Results}

While the students were well informed ahead of time about the OBOW exam that will be taken by the end of the semester, they expressed some anxiety and concerns at the beginning especially that the exam was supposed to be conducted individually and off campus. Their major concern was that in case they encounter any technical problem, they will be by themselves and could not complete the task on time which could result in a poor performance. Despite these worries, some others welcomed the idea and considered it as an opportunity and a new challenge to accomplish the required tasks (for a reason or another) and thought that it would be easier than the traditional method (see Table 3). 
Table 3. Focus groups results concerning emotional tension/ anxiety

$\begin{aligned} & \text { It was difficult for me to accept the idea. I had fears }{ }^{1} \text { and concerns } \\ & \text { (Female Student from group 1- school 1). }\end{aligned}$
$\begin{aligned} & \text { I felt some tension', but it was ok. I like technology and don't have } \\ & \text { any problem dealing with it (Female Student from group 2- school 2). } \\ & \text { tension- } \\ & \text { anxiety }\end{aligned}$
$\begin{aligned} & \text { It isn't easy at all. There shouldn't be a problem. I personally didn't } \\ & \text { encounter any problem at all.(Female Student from group 2- school } \\ & \text { 3). }\end{aligned}$

Another factor emerged to be very important and in favor of OBOW: self-efficacy. When a student experiences anxiety during an exam, his mood activates the memories that are consistent with it. The negative mood provokes previous failures or negative experiences which could lead to a lower believe in their self-efficacy (Richardson et al., 2012). Therefore, when asked about their self-efficacy, during and before the exam, students described the feeling as excellent or as bad depending on their situation. Those who had negative feelings and expressed anxiety had resulted in lower self-esteem and believe in their self-efficacy sometimes and those who had high self-efficiency feeling, were less stressed and perceived well the ease of usefulness of such a method.

Table 4. Focus groups results concerning anxiety, self-efficacy, perceived ease of use, attitude towards using the system

\begin{tabular}{|c|c|c|}
\hline $\begin{array}{l}\text { When the online exam started, I was really confused }{ }^{1} \text {. I heard from other } \\
\text { students that as a first time user, it wouldn't be easy for me }{ }^{2} \text {. I panicked for } \\
\text { the first } 15 \mathrm{mn} \text {. This was too complex for me. }{ }^{1} \text { I didn't even score as I } \\
\text { anticipated I really think this method is difficult }{ }^{3} \text { and not very useful }{ }^{3} \text { for } \\
\text { me to use in the future... I would consider using }{ }^{4} \text { it in the future maybe if } \\
\text { things get better (Female student from group } 1-\text { school } 1 \text { ). }\end{array}$ & $\begin{array}{l}\text { 1-Emotional tension- } \\
\text { anxiety } \\
\text { 2-Self-efficacy } \\
\text { 3-Perceived ease of } \\
\text { use. } \\
\text { 4-Attitude towards } \\
\text { using the system }\end{array}$ & $\begin{array}{l}\text { Richardson et } \\
\text { al., 2012; }\end{array}$ \\
\hline
\end{tabular}

The last topic that was discussed with them was the possible attitude towards using an online mean to conduct an exam based on their experience. Whether they would repeat the experience or not, and the antecedents that could affect their attitude whether negative or positive.

Table 5. Focus groups results concerning anxiety, self-efficacy, perceived ease of use, attitude towards using the system

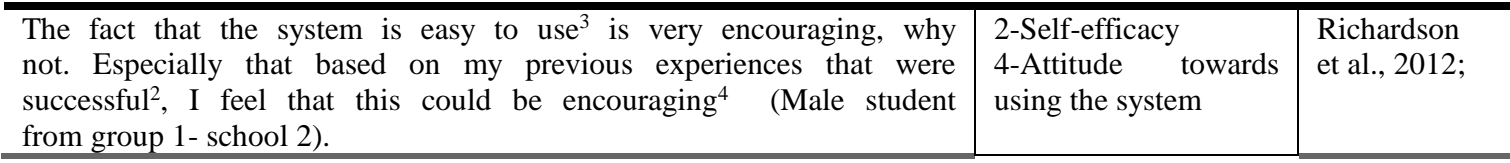

We have identified several factors and organized them randomly then sent them to a group of 307 students from the same sample. They were solicited by emails, and a set of 10 questions were asked and the students were expected to answer on a Likert scale from 1 to 5 (see table 6).

Table 6. Gender difference responses

\begin{tabular}{|l|l|l|}
\hline & Male $(\mathrm{n}=101)$ & Female $(\mathrm{n}=110)$ \\
\hline Emotional -tension- anxiety (ETANX) & 3.1 & 4.2 \\
\hline Perceive Ease of Use ( PEU) & 4.2 & 2.88 \\
\hline Attitude towards e-learning ( A) & 3.9 & 2.4 \\
\hline Self-efficacy (SEF) & 4.2 & 2.77 \\
\hline
\end{tabular}

Note: 5 -point Likert scale scoring system used: $5=$ strongly agree, $4=$ agree, $3=$ neutral, $2=$ disagree, $1=$ strongly disagree. 


\section{SUMMARY AND CONCLUSION}

Our main concern was investigating the experience and the factors that could affect the academic performance of OBOW exams by comparing them with the traditional closed book exams. Obviously, we were neither after harassing students nor filtering them. The progress in the teaching methods that appeared recently had driven many scholars to identify the best way to examine students and the OBOW was one of those methods (Baird et al, 2019). When observing the performance of the models (Tables 1 and 2), it is observed that there isn't much difference in the results. As for the cheating, we have suspected 4 cases in the OBOW based on the software results and tracking system compared to 5 cases in the traditional exam that were detected by the instructors. Comparing the results together, we can assert that the results of the exams in both methods were credible to investigate which could help us conclude, that the risk of cheating in the OBOW is about just the same as in traditional exams. The results in the second phase show an evident improvement with the OBOW model where the students had all the resources available in an exam that required a personal effort and was made at their convenience in a stress free environment. Based on the above stated results, we observe that the OBOW method is efficient if not more than the traditional method at least the same. Such method can pave the way for students to get ready for the real-world problems by giving them more motivation and confidence in a stress free environment and helping them in getting engaged with multi-media and depth in learning. Thus, and a result of the semi structured interviews and questionnaires that were sent, three important factors predicted the attitude towards OBOW exams: emotional tension- anxiety, self-efficacy, perceived ease of use and last but not least the gender difference as well. Thus, we propose the below model that should to be tested on a larger scale for more validity.

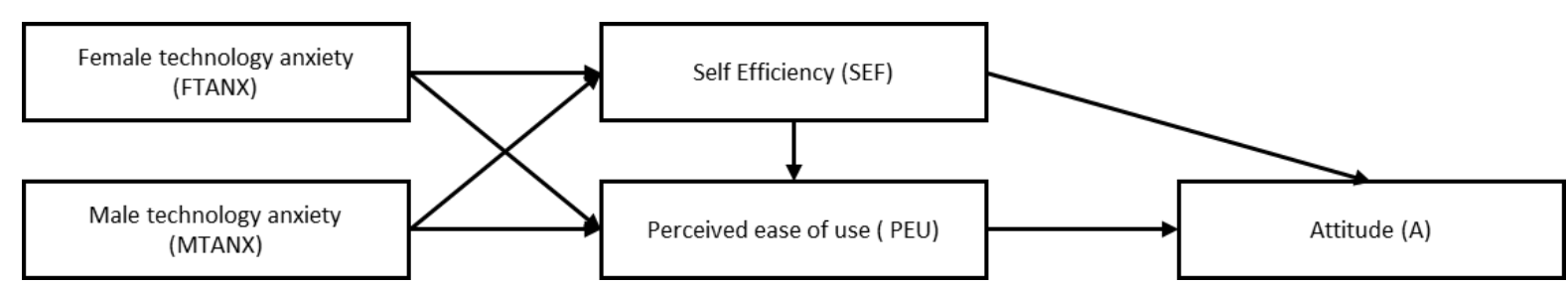

Figure 1. Proposed Model

\section{LIMITATIONS}

The current research had allowed us to shed the light on a topic that is still incomprehensible. An ongoing research concerning the Open Book Open Web exam method has given positive results concerning students' own perception and experience and was compared with the traditional examination method results. Furthermore, an attempt to compare test results as described earlier was done. Like any other research, this study has some limitations. The current study could be carried out on a larger sample to take into consideration different cases and analyze it with a quantitative method in order to have a more solid result.

\section{REFERENCES}

Baird, M., Sefcik, L., Steyn, S., \& Price, C., 2019. Learning Analytics Leading to Remote Invigilation for eTests: A Case Study. In Utilizing Learning Analytics to Support Study Success. Springer, Cham. pp. 295-312.

Davis, F. D., 1989. Perceived Usefulness, Perceived Ease of Use, and User Acceptance of Information Technology. MIS quarterly, pp.319-340.

El Rassi, M. A. B., 2020. Why one e-business adoption model won't fit all firm sizes: The case of Lebanon's e-service industry. The Electronic Journal of Information Systems in Developing Countries, e12135.

El Rassi, M, 2018. Firm's Size Effect in the e-Service Industry: The Case of a Developing Country. AIS electronic library (AISeL).https://aisel.aisnet.org/cgi/view content.cgi?article=1013\&context=ecis2018_rp

El Rassi, M. A. B., \& Harfouche, A., 2016. E-Business Assimilation Levels in Lebanon. In Information and Communication Technologies in Organizations and Society. Springer, Cham. pp. 141-160. 
Fishbein, M. \& Ajzen,I.,1975 . Belief, Attitude, Intention and Behavior: An Introduction to Theory and Research, 181-202.

Guàrdia, L., Crisp, G., \& Alsina, I., 2017. Trends and Challenges of E-Assessment to Enhance Student Learning in Higher Education. In Innovative Practices for Higher Education Assessment and Measurement IGI Global. pp. 36-56.

Howard, G. S., \& Smith, R. D., 1986. Computer Anxiety in Management: Myth or Reality?. Communications of the ACM, 29(7), pp. 611-615.

Hung, C. M., Huang, I., \& Hwang, G. J., 2014. Effects of Digital Game-Based Learning on Students' Self-Efficacy, Motivation, Anxiety, and Achievements in Learning Mathematics. Journal of Computers in Education, 1(2-3), 151-166.

Joi,L.M., Camille,D.D.\& Krista, G (2011). E-Learning, Online Learning and Distance Learning Environments: Are they the Same? Internet High Educ, 14,129-135.

Madorin, S., \& Iwasiw, C.,1999. The Effects of Computer-Assisted Instruction on the Self-Efficacy of Baccalaureate Nursing Students. Journal of nursing education, 38(6), pp.282-285.

Miller, A., \& Young-Jones, A. D., 2012. Academic Integrity: Online Classes Compared to Face-to-Face Classes. Journal of Instructional Psychology, 39(3).

Ndubisi, N. O., 2004. Factors Influencing E-Learning Adoption Intention: Examining the Determinant Structure of the Decomposed Theory of Planned Behaviour Constructs. In Proceedings of the 27th Annual Conference of HERDSA (pp. 252-262).

Richardson, M., Abraham, C., \& Bond, R., 2012. Psychological Correlates of University Students' Academic Performance: A Systematic Review and Meta-Analysis. Psychological Bulletin, 138 (2), 353.

Roca J.C, Chiu C-M. and Martinez F.J, 2006. Understanding e-Learning Continuance Intention: An Extension of the Technology Acceptance Model. International Journal of Human-Computer Studies, 64 (8), pp. 683-696.

Saadé, R. G., \& Kira, D., 2006. The Emotional State of Technology Acceptance. Issues in Informing Science \& Information Technology, 3.

Simonson, M. R., Maurer, M., Montag-Torardi, M., \& Whitaker, M., 1987. Development of a Standardized Test of Computer Literacy and a Computer Anxiety Index. Journal of educational computing research, 3(2), pp. 231-247.

Steve, G., Ferrante, C. J., and Heppard, K.A., 2016. Using Open-Book Exams to Enhance Student Learning Performance, and Motivation.

Venkatesh, V., Morris, M. G., Davis, G. B., \& Davis, F. D., 2003. User acceptance of Information Technology: Toward a Unified View. MIS quarterly, pp. 425-478. 